\title{
Purification and Characterization of Acinetobacter calcoaceticus 4-Hydroxybenzoate 3-Hydroxylase after Its Overexpression in Escherichia coli ${ }^{1}$
}

\author{
Javier Fernandez, ${ }^{*, 2}$ Anthony A. Dimarco, ${ }^{\dagger}$ L. Nicholas Ornston, ${ }^{\dagger}$ and Shigeaki Harayama ${ }^{*, 3}$ \\ *Department of Medical Biochemistry, University Medical Center, 1 rue Michel Servet, 1211 Geneva, Switzerland; \\ and ${ }^{\dagger}$ Department of Biology, Yale University, New Haven, CT 06511, USA
}

Received for publication, January 20, 1995

\begin{abstract}
4-Hydroxybenzoate 3-hydroxylase [EC 1.14.13.2] from Acinetobacter calcoaceticus was purified to homogeneity following the 40 -fold overexpression of this gene (pobA) in Escherichia coli. Overexpression was accomplished by placing the folA gene (encoding trimethoprim-resistant dihydrofolate reductase) directly downstream of the pobA gene, and demanding growth of recombinants on elevated concentration of trimethoprim. Presumably, the surviving variants have undergone a genetic alteration which allowed the overexpression of both folA and pobA. 4-Hydroxybenzoate 3-hydroxylase was purified in two chromatographic steps, characterized biochemically, and its properties were compared to those of its homolog from Pseudomonas fluorescens. The two enzymes differ in their reponse to $\mathrm{Cl}^{-}$ion inhibition. A single amino acid change in the putative NADPH-binding site is proposed to account for this difference. The inhibitory and catalytic properties of substrate analogs were also examined.
\end{abstract}

Key words: Acinetobacter calcoaceticus, dihydrofolate reductase, 4-hydroxybenzoate 3hydroxylase, overexpression, pobA.

4-Hydroxybenzoate 3-hydroxylase is a monooxygenase which converts 4 -hydroxybenzoate to protocatechuate for further metabolism by one of the two branches of the $\beta$ ketoadipate pathway. The complete amino acid sequences of the isofunctional 4-hydroxybenzoate 3-hydroxylases from Pseudomonas fluorescens and Pseudomonas aeruginosa have been determined (1-6). The three-dimensional structure of the oxidized Pseudomonas enzymes complexed with the substrate has been elucidated $(7-9)$ as well as the structures of the substrate-free enzyme, the reduced enzyme complexed with the substrate and the enzymeproduct complex $(10,11)$. Identification of the amino acid residues of this enzyme which may be important for substrate recognition, co-factor binding and enzyme catalysis has been derived from X-ray crystallography data and computer-modelling analysis $(7,12)$. Furthermore, chemical modification and site-directed mutagenesis elucidated the roles of some residues in the catalytic reaction $(5,13$, 14).

Recently, we have cloned the structural (pobA) and regulatory (pobR) genes for 4-hydroxybenzoate 3-hydrox-

\footnotetext{
This work was supported by Swiss National Science Foundation and the United States Army Research Office. J.F. was supported by a postdoctoral fellowship from European Environmental Research Organization. A.A.D. was supported by a postdoctoral fellowship (PF-3543) from the American Cancer Society.

${ }^{2}$ Present address: Department of Molecular Biochemistry and Biology, Faculty of Veterinary Science, Universidad Complutense, Madrid, Spain.

${ }^{3}$ To whom correspondence should be addressed at the present address: Marine Biotechnology Institute, Kamaishi Laboratories, 375-1 Heita, Kamaishi, Iwate 026, Japan. Tel: +81-193-26-6544, FAX: $+81 \cdot 193 \cdot 26 \cdot 6592$
}

ylase of Acinetobacter calcoaceticus (15) and determined the nucleotide sequence $(16,17)$. The deduced amino acid sequence shows that 4-hydroxybenzoate 3 -hydroxylase from $A$. calcoaceticus is a single polypeptide of 404 amino acid residues. While the pobA nucleotide sequence from $A$. calcoaceticus is very different from the pobA genes in the Pseudomonas species (42\% identity), the amino acid sequence of the Acinetobacter enzyme shows $64 \%$ identity ( $90 \%$ overall similarity) to the enzyme from $P$. fluorescens. Nevertheless several replacements occur at or near the active site, or at positions where cofactor binding is believed to occur, suggesting that the Acinetobacter enzyme may exhibit different properties from the previously characterized Pseudomonas enzymes. This paper reports the purification and characterization of 4-hydroxybenzoate 3-hydroxylase produced from the $A$. calcoaceticus pobA gene cloned in Escherichia coli.

\section{MATERIALS AND METHODS}

Materials-Growth media were supplied by Difco (USA). Antibiotics, NADPH, and FAD were from Sigma Chemical (USA), and 4-hydroxybenzoate, its structural analogs, and various chemicals were purchased either from Fluka AG (Switzerland) or Aldrich (Germany). A TSK-Gel DEAE-5PW column $(150 \times 21.5 \mathrm{~mm})$ and a Bio-Sil TSK250 gel filtration column $(300 \times 7.5 \mathrm{~mm})$ were from Tosoh (Japan), while Mitsui-Toatsu (Japan) supplied an HCAhydroxyapatite column $(100 \times 7.6 \mathrm{~mm})$. The Bio-Rad protein assay kit and the protein standards for gel filtration chromatography were purchased from Bio-Rad Laboratories (USA). Pharmacia (Sweden) supplied the protein 
standards for SDS/polyacrylamide gel electrophoresis.

Bacterial Strains, Plasmids, and Culture ConditionsCultures of the wild-type strain of $A$. calcoaceticus ADP1 (18) were grown in minimal medium M9 (19) supplemented with minor elements (20) and $5 \mathrm{mM} 4$-hydroxybenzoate as a source of carbon and energy. $E$. coli JM83 and JM101 (21) cultures were grown in Luria-broth under appropriate antibiotic selection. The plasmids used are shown in Fig. 1. The induction of the $\mathrm{T} 7$ promoter was carried out as described (22).

Isolation of Plasmid DNA-Plasmid DNA was purified from $E$. coli JM101 by the alkaline lysis procedure (23) with cesium chloride-ethidium bromide density gradient centrifugation. The same method without density gradient centrifugation was used for mini-scale preparations of plasmids.

Preparation of Cell-Free Extract-4-Hydroxybenzoate 3-hydroxylase was prepared from cultures of JM83(pZR4057) grown in 3 liter of Luria-broth containing ampicillin $(100 \mathrm{~g} / \mathrm{ml})$. Following inoculation with a preculture of JM83(pZR4057) grown in the same medium, the culture was incubated aerobically at $37^{\circ} \mathrm{C}$ with shaking, and harvested at the late logarithmic phase of growth (14-15 h). The yield was approximately $3-4 \mathrm{~g}$ wet cells per liter. The cells were washed twice with $20 \mathrm{mM}$ potassium phosphate buffer (pH 7.2) containing $0.3 \mathrm{mM}$ EDTA, resuspended in 1/100 initial volume of the same buffer, and ruptured by two passages through a precooled French press (SLM Instruments, USA) with a pressure differential of 76 $\mathrm{MPa}$ at the orifice. The broken-cell preparation was centrifuged at $20,000 \times g$ at $4^{\circ} \mathrm{C}$ for $20 \mathrm{~min}$ to remove the cell debris, and the supernatant was further centrifuged at $100,000 \times g$ at $4^{\circ} \mathrm{C}$ for $60 \mathrm{~min}$ in a Beckman $60 \mathrm{Ti}$ rotor.

- Purification of 4-Hydroxybenzoate 3-Hydroxylase-The cell extract was applied to a TSK-BioGel DEAE-5PW anion-exchange column $(150 \times 21.5 \mathrm{~mm})$ preequilibrated in $20 \mathrm{mM}$ potassium phosphate buffer ( $\mathrm{pH} 7.2)$. The enzyme was eluted by a linear gradient of 0 to $0.5 \mathrm{M} \mathrm{Na}_{2} \mathrm{SO}_{4}$ in 300 $\mathrm{ml}$ of $20 \mathrm{mM}$ potassium phosphate buffer (pH 7.2) at a flow rate of $5 \mathrm{ml} / \mathrm{min}$. The active fractions were combined and filtered through a Nalgene nitrocellulose membrane $(0.45$ $\mu \mathrm{m}$ pore size). The addition of exogenous $\mathrm{FAD}$ to these fractions increased the apparent activity of 4-hydroxybenzoate 3-hydroxylase, indicating that a fraction of 4-hydroxybenzoate 3-hydroxylase had been resolved of FAD. Prior to further purification, the active fraction was incubated with an excess amount of FAD ( $1 \mathrm{mM})$ for $30 \mathrm{~min}$ to reconstitute the FAD-bound enzyme. This preparation was applied to a Bio-Gel P-6-D column (Bio-Rad) preequilibrated with $20 \mathrm{mM}$ phosphate buffer ( $\mathrm{pH} 7$ ), and eluted with the phosphate buffer. Almost all the enzyme applied was recovered in the first $3 \mathrm{ml}$, while free $\mathrm{FAD}$ was eluted later. The enzyme solution was subsequently diluted with water to reduce the concentration of phosphate buffer to 10 $\mathrm{mM}$, loaded onto an HCA-hydroxyapatite column preequilibrated with $10 \mathrm{mM}$ potassium phosphate buffer $(\mathrm{pH}$ 7 ), and eluted with the starting buffer at a flow rate of $1 \mathrm{ml} /$ min. Unlike the majority of other proteins, 4-hydroxybenzoate 3-hydroxylase was not adsorbed. Yellow fractions containing enzyme activity were collected and stored at $-70^{\circ} \mathrm{C}$ until used.

Gel Filtration Chromatography-Molecular weight of the native enzyme was estimated on a Bio-Sil TSK-250 gel filtration column calibrated with Bio-Rad gel filtration standards; samples were run in $50 \mathrm{mM}$ potassium phosphate buffer $\mathrm{pH} 7$ containing $0.15 \mathrm{M} \mathrm{NaCl}$ at a flow rate of $0.3 \mathrm{ml} / \mathrm{min}$. The standard proteins were thyroglobulin $(670$ $\mathrm{kDa})$, gamma globulin (158 kDa), ovalbumin $(44 \mathrm{kDa})$, myoglobin $(17 \mathrm{kDa})$, and vitamin $\mathrm{B}_{12}(1.35 \mathrm{kDa})$.

Polyacrylamide Gel Electrophoresis-Gel electrophoresis of purified 4-hydroxybenzoate 3-hydroxylase was carried out in a $12 \%(\mathrm{w} / \mathrm{v})$ polyacrylamide slab gel containing $0.1 \%(\mathrm{w} / \mathrm{v})$ sodium dodecyl sulfate (SDS) using $375 \mathrm{mM}$ Tris- $\mathrm{HCl}(\mathrm{pH} \mathrm{8)}$. After the run, the gel was stained with $0.1 \%(\mathrm{w} / \mathrm{v})$ Coomassie Blue R250 in an aqueous solution containing $30 \%(\mathrm{v} / \mathrm{v})$ methanol and $10 \%(\mathrm{v} / \mathrm{v})$ acetic acid for $1 \mathrm{~h}$, and destained in $30 \%(\mathrm{v} / \mathrm{v})$ methanol/10\% (v/v) acetic acid. The molecular mass of the enzyme was obtained from a comparison of its relative mobility to those of the standard proteins (phosphorylase $b, 94 \mathrm{kDa}$; albumin, 67 $\mathrm{kDa}$; ovalbumin, $43 \mathrm{kDa}$; carbonic anhydrase, $30 \mathrm{kDa}$; trypsin inhibitor, $20.1 \mathrm{kDa}$; and $\alpha$-lactalbumin, $14.4 \mathrm{kDa}$ ).

Protein Assay-Protein concentration was determined by the method of Bradford (24) using a Bio-Rad protein assay kit with bovine gamma globin as a standard. Protein from column effluents was monitored by measuring the absorbance at $280 \mathrm{~nm}$.

Enzyme Assay-The enzyme activity was assayed spectrophotometrically using a Uvikon 940 double beam spectrophotometer (Kontron, Switzerland) by following the decrease in absorbance at $340 \mathrm{~nm}$ due to the oxidation of $\mathrm{NADPH}$ to $\mathrm{NADP}^{+}$. Assay reactions were performed at $25^{\circ} \mathrm{C}$ in $50 \mathrm{mM}$ Tris-ammonium acetate ( $\left.\mathrm{pH} 8\right)$, containing $0.14 \mathrm{mM} 4$-hydroxybenzoate, $0.14 \mathrm{mM} \mathrm{NADPH}$, and $1 \mathrm{M}$ FAD, and were initiated by addition of the enzyme. The rate of oxidation was measured during the first minute. The effect of $\mathrm{pH}$ on the enzymatic activity of 4-hydroxybenzoate 3 -hydroxylase was determined in the standard assay conditions described above except that the following buffers were used: $50 \mathrm{mM}$ Tris-ammonium acetate for $\mathrm{pH}$ 6.5 to $8.5,50 \mathrm{mM}$ potassium phosphate for $\mathrm{pH} 6$ to 8 , and $50 \mathrm{mM}$ Tris-sulfate for $\mathrm{pH} 7$ to 9 .

Determination of $N$-Terminal Sequence-The N-terminal amino acid sequencing of 4-hydroxybenzoate 3-hydroxylase by Edman degradation was carried out on an automated protein sequencer (model 477, Applied Biosystems, USA).

\section{RESULTS}

Expression of pobA in $A$. calcoaceticus and $E$. coliMeasured levels of 4-hydroxybenzoate 3-hydroxylase synthesized in the natural host, $A$. calcoaceticus ADP1, and in $E$. coli (JM83) containing the cloned pobA gene (pZR405) were very low compared to levels observed in $P$. fuorescens $(25,26)$ and in $P$. aeruginosa (27) (Table I). Assuming that the specific activity of the pure enzyme from $A$. calcoaceticus is similar to that from $P$. fluorescens, the cell-free extracts of $A$. calcoaceticus and of $E$. coli (pZR405) contain 4-hydroxybenzoate 3 -hydroxylase constituting only $0.1 \%$ of the total protein. In order to overexpress the pobA gene of $A$. calcoaceticus, we subcloned it into different vectors under the regulatory control of the lac- or T7 promoter. The 2.3-kb EcoRI-NsiI fragment containing the entire pobA gene was cloned into pUC19 between the EcoRI and PstI sites. This plasmid was designated pZR4053 (Fig. 1). 
This construct, however, allowed the expression of $p o b A$ at only moderate levels (Table I). The pobA gene was also cloned under the T7 promoter, to construct p'T762. 4-Hydroxybenzoate 3-hydroxylase was, however, not overproduced under the conditions under which T7 RNA polymerase was overproduced (Table I). The failure of the strong promoters to overexpress pobA may be due to the presence of a transcriptional termination signal upstream of the $p o b A$ gene. To remove this putative transcriptional termination signal, we constructed the plasmid pZR4054 in which the 0.8 -kb EcoRI fragment of pBS618 containing the trimethoprim-resistant tetrahydrofolate reductase gene (folA) from $P$. putida was cloned into the EcoRI site (downstream of pobA) of pZR4053 in the same orientation relative to the lac promoter of pUC19 (Fig. 1). Genetic alterations which increase the expression of both $p o b A$ and

TABLE I. The activity of 4-hydroxybenzoate 3-hydroxylase in crude extracts.

\begin{tabular}{llc}
\hline Strain & \multicolumn{1}{c}{ Medium $^{*}$} & $\begin{array}{c}\text { Specific activities } \\
\text { in cell extracts }\end{array}$ \\
\hline A. calcoaceticus ADP1 & Succinate minimal & 1 \\
A. calcoaceticus ADP1 & 4-HBA minimal & 50 \\
E. coli JM83(pZR405) & L-broth +4-HBA & 45 \\
E. coli JM83(pZR4053) & L-broth & 40 \\
E. coli JM101(pT762) & L-broth & 100 \\
E. coli JM83(pZR4054) & L-broth & 65 \\
E. coli JM83(pZR4057) & L-broth & 1,820 \\
\hline
\end{tabular}

'The concentrations of succinate and 4-hydroxybenzoate (4-HBA) used were $10 \mathrm{mM}$ and $5 \mathrm{mM}$, respectively. ${ }^{b} \mu \mathrm{mol} \mathrm{NADPH}$ oxidized. $\min ^{-1} \cdot \mathrm{mg}$ protein ${ }^{-1}$.
foLA may allow the host to resist higher concentrations of trimethoprim. About $10^{8}$ cells of JM101(pZR4054) were spread onto plates containing $300 \mu \mathrm{g} / \mathrm{ml}$ trimethoprim. Whereas $E$. coli JM83 containing pZR4054 was resistant to trimethoprim at $100 \mu \mathrm{g} / \mathrm{ml}$ but sensitive to $300 \mu \mathrm{g} / \mathrm{ml}$, three colonies developed with resistance to $300 \mu \mathrm{g} / \mathrm{ml}$. The plasmids in these colonies were analyzed and one was selected for further analysis (pZR4056; Fig. 1). When the 4-hydroxybenzoate 3-hydroxylase activities in the cultures of JM83(pZR4054) and JM83(pZR4056) were measured, the activity in JM83(pZR4056) was 40 -fold higher than that found in JM83(pZR4054). The EcoRI-HindIII fragment of the pZR4056 plasmid containing the pobA gene was then subcloned into pUC19 between the EcoRI and HindIII sites. The resulting plasmid pZR4057 (Fig. 1) was used to transform JM83, and the transformant, JM83(pZR4057), expressed 4-hydroxybenzoate 3-hydroxylase at a level of $1,820 \mathrm{mU} / \mathrm{mg}$ protein, 40 -fold higher than the induced level of $A$. calcoaceticus (Table I). Restriction analysis of pZR4053 and pZR4057 plasmids revealed no detectable difference in size, suggesting that a point mutation or a short insertion/deletion (less than $50 \mathrm{bp}$ ) may be respon. sible for the overexpression of $p o b A$.

Purification of 4-Hydroxybenzoate 3-Hydroxylase-The 4-hydroxybenzoate 3-hydroxylase was purified to homogeneity in two chromatograpic steps as described in " MATE. RIALS AND METHODS." The procedure gave about 20-fold purification with a yield of $76 \%$ (Table II), and a specific activity of 35 to 40 units per $\mathrm{mg}$ protein. This activity is similar to that previously reported for $P$. fluorescens (26)
Plasmid Vector



pZR405

pUC18
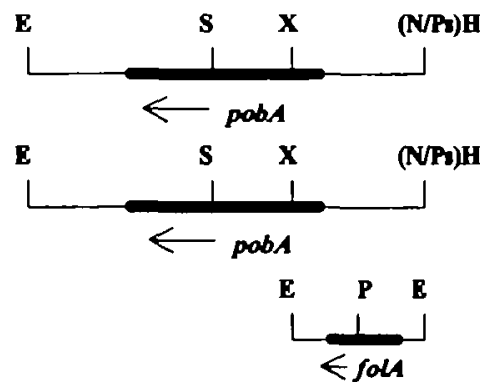

pZR4053

pUC19

pT762

pT7-6

pBS618

pBS8

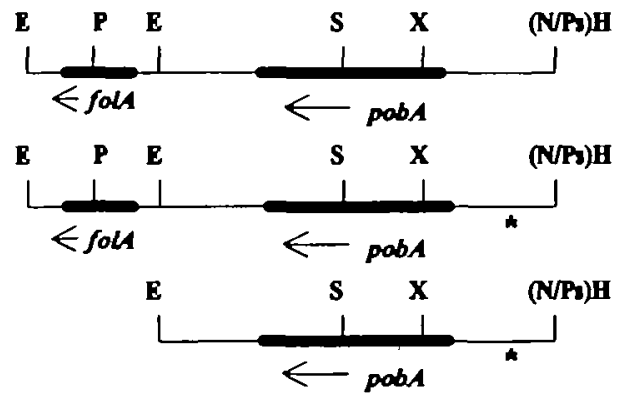

pZR4054 pUC19

pZR4056 pUC19

pZR4057 pUC19

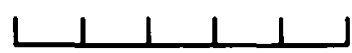

5 kb
Fig. 1. Plasmids used in this study. Only DNA inserts are presented in this figure. Abbreviations: A, AccI; E, EcoRI; H, HindIII; N, NsiI; P, PvuII; S, SphI; X, XhoI; Ps, PstI. $(\mathrm{N} / \mathrm{Ps}) \mathrm{H}$ indicates that the $\mathrm{N} 8 \mathrm{II}$ site upstream of pobA was ligated to the PstI site of the multiple cloning site of pUC19, which also contains the HindIII site. Between the NsiI site and the initiation codon of $p o b A$, a transcription termination signal may exist. This signal is modified in pZR4056 and pZR4057, and asterisks (*) indicate the modification. folA is the structural gene for trimethoprim-resistant tetrahydrofolate reductase from $P$. putida. 
TABLE II. Purification of 4-hydroxybenzoate 3-hydroxylase from $E$. coli JM83(pZR4057).

\begin{tabular}{lcccccc}
\hline Step & $\begin{array}{c}\text { Volume } \\
(\mathrm{ml})\end{array}$ & $\begin{array}{c}\text { Protein } \\
(\mathrm{mg})\end{array}$ & $\begin{array}{c}\text { Total } \\
\text { activity }\end{array}$ & $\begin{array}{c}\text { Specific } \\
\text { activity }\end{array}$ & $\begin{array}{c}\text { Yield } \\
(\%)\end{array}$ & $\begin{array}{c}\text { Purification } \\
\text { (fold) }\end{array}$ \\
\hline Cell-extract & 30 & 1,100 & 2,000 & 1.8 & 100 & 1 \\
DEAE·5PW & 20 & 130 & 1,900 & 14 & 95 & 7.7 \\
Hydroxyapatite & 30 & 40 & 1,500 & 38 & 76 & 20 \\
\hline
\end{tabular}

$\mu \mathrm{mol} \mathrm{NADPH}$ oxidized $\cdot \mathrm{min}^{-1} \cdot{ }^{\mathrm{b}} \mu \mathrm{mol} \mathrm{NADH}$ oxidized $\cdot \mathrm{min}^{-1} \cdot \mathrm{mg}^{-1}$.



Fig. 2. Effect of pH on the activity of 4-hydroxybenzoate 3hydroxylase. The buffers used were ([ ]) potassium phosphate 50 $\mathrm{mM} ;(\diamond)$ Tris-sulfate $50 \mathrm{mM}$; and (a) Tris-ammonium acetate 50 $\mathrm{mM}$. The activity is expressed as $\mathrm{mol} \mathrm{NADPH}$ oxidized $\cdot \mathrm{min}^{-1} \cdot \mathrm{mg}$ protein $^{-1}$

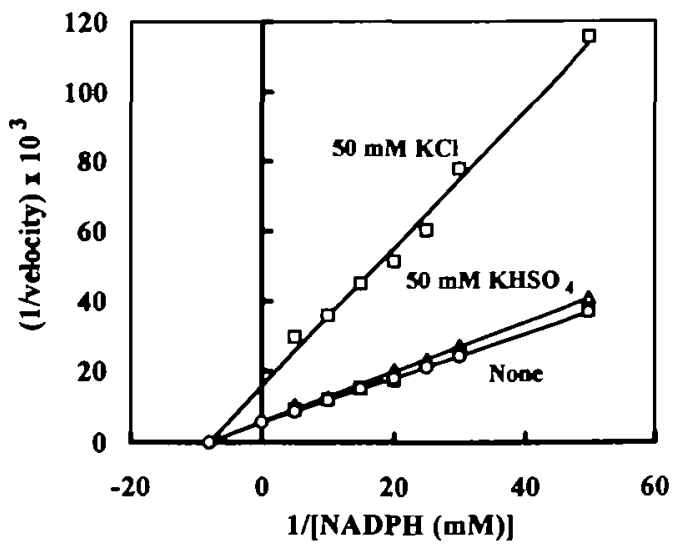

Fig. 3. Inhibition of the 4-hydroxybenzoate 3-hydroxylase activity by $\mathrm{KCl}$. The initial velocity of the NADPH oxidation by 4-hydroxybenzoate 3-hydroxylase was measured with varying concentrations of NADPH in $50 \mathrm{mM}$ Tris-ammonium acetate buffer $\mathrm{pH}$ 8.0 or in the same buffer containing either $50 \mathrm{mM} \mathrm{KCl}$ or $50 \mathrm{mM}$ KHSO. The $K_{\mathrm{a}}$ for NADPH was unchanged under these conditions.

and $P$. aeruginosa (27) enzymes. The fractions obtained from the hydroxyapatite column were subjected to gel electrophoresis under denaturing conditions. In the first $3-\mathrm{ml}$ fractions, only a single band of the molecular mass of $45 \mathrm{kDa}$ was present, whereas in the succesive $3-\mathrm{ml}$ fractions, two bands of similar molecular mass were present. This difference in the electrophoretic mobility may not be due to a difference in the molecular mass of the enzyme but the partial oxidation of Cys-122 as has been reported for the $P$. fluorescens enzyme (Cys-116) (28).

One difficulty we encountered during the purification was a loss of activity due to the unintentional resolution of FAD
TABLE III. Kinetic parameters of p-hydroxybenzoate hydroxylase.

\begin{tabular}{lcc}
\hline Substrate & $\begin{array}{c}K_{\mathrm{m}} \\
(\mu \mathrm{M})\end{array}$ & $\begin{array}{c}V_{\max } \\
\text { apparent }\end{array}$ \\
\hline 4-HBA & 41 & 48.5 \\
2,4-DHBA & 250 & 1.5 \\
3-Cl-4-HBA & 180 & 3.2 \\
\hline Inhibitor & Type of inhibition & $K_{1}$ \\
& & $(\mu \mathrm{M})$ \\
\hline 2,4-DHBA & Competitive & 310 \\
3-Cl-4.HBA & Mixed & $\mathrm{ND}$ \\
3,4-DHBA & Competitive & 550 \\
4-Aminobenzoate & Competitive & 50 \\
Benzoate & Competitive & 530 \\
\hline
\end{tabular}

"Abbreviations: 4-HBA, 4-hydroxybenzaate; 2,4-DHBA, 2,4-dihydroxybenzoate; 3-Cl-4-HBA, 3-chloro-4-hydroxybenzoate; 3,4DHBA, 3,4-dihydroxybenzoate. 'The activity ( $\mu \mathrm{mol}$ NADPH oxidized $\cdot \mathrm{min}^{-1} \cdot \mathrm{mg}^{-1}$ ) was determined under the standard conditions except that the concentration of 4-hydroxybenzoate or its analogue was varied. 'ND: not determined.

from the enzyme following chromatography on DEAE-5PW resin. This effect was also observed with hydrophobic interaction chromatography (data not shown). In both cases, activity was restored by incubating the enzyme solution in the presence of excess FAD.

The molecular weight of the enzyme estimated by gel filtration chromatography was 89,000 indicating that the enzyme exists as a dimer. The $\mathrm{N}$-terminal sequence of the purified protein was MQTMKTKVAI, which confirmed the previous assignment of the initiation codon of the pobA gene (16).

Characterization of 4-Hydroxybenzoate 3-HydroxylaseExposure of the enzyme to temperature above $50^{\circ} \mathrm{C}$ for 10 min resulted in its rapid inactivation (60\% inactivation), but the presence of its substrate offered some protection: in the presence of $0.1 \mathrm{mM} 4$-hydroxybenzoate, the enzyme retained $80 \%$ of its activity after heating at $50^{\circ} \mathrm{C}$ for $10 \mathrm{~min}$. Likewise, in the presence of 4-hydroxybenzoate, FAD and EDTA, the enzyme lost only $10 \%$ of its activity after incubation at $4^{\circ} \mathrm{C}$ for $24 \mathrm{~h}$, whereas incubation in the absence of these components resulted in a $40 \%$ loss of activity. These observations are in agreement with the results published for the enzymes from $P$. fluorescens (29) and from $P$. aeruginosa (27).

The optimum $\mathrm{pH}$ for 4-hydroxybenzoate 3 -hydroxylase was 8.0 (Fig. 2) and is consistent with the $\mathrm{pH}$ optimum of 8.0 reported for the $P$. aeruginosa $(27)$ and $P$. fluorescens (26) enzymes. The enzyme activity was about $50 \%$ lower in $50 \mathrm{mM}$ potassium phosphate buffer ( $\mathrm{pH} \mathrm{8.0)}$ and $50 \mathrm{mM}$ Tris-sulfate buffer ( $\mathrm{pH} \mathrm{8.0)}$ than in $50 \mathrm{mM}$ Tris-ammonium acetate buffer (pH 8.0) (Fig. 2). We also tested the effect of salts on 4-hydroxybenzoate 3-hydroxylase activity in $50 \mathrm{mM}$ Tris-ammonium acetate buffer ( $\mathrm{pH} 8$ ). Addition of $50 \mathrm{mM} \mathrm{KCl}$ inhibited $60 \%$ of the enzyme activity, but 50 $\mathrm{mM} \mathrm{KHSO}_{4}$ did not exhibit any significant inhibition (Fig. 
3). The inhibition by the chloride ion was non-competitive to NADPH: the apparent $K_{\mathrm{m}}$ for NADPH was not influenced by $\mathrm{KCl}$.

4-Hydroxybenzoate 3-hydroxylase from $A$. calcoaceticus oxidized NADPH in the presence of 4-hydroxybenzoate, but no activity was seen with NADH. The purified enzyme was also highly specific to 4 -hydroxybenzoate. Of several analogs tested, only 2,4-dihydroxybenzoate and 3-chloro-4hydroxybenzoate served as substrates, but the enzymatic activity with these compounds was very low. The results are summarized in Table III. The maximum activity of 4-hydroxybenzonte 3-hydroxylase was observed around $0.14 \mathrm{mM}$ 4-hydroxybenzoate. At concentrations higher than $1 \mathrm{mM}$, the substrate was inhibitory.

A number of compounds structurally related to 4-hydroxybenzoate were competitively inhibitory to the oxidation of 4-hydroxybenzoate (Fig. 4). The inhibition caused by 3-chloro-4-hydroxybenzoate was mixed type. Compounds which caused over $60 \%$ of inhibition at $1 \mathrm{mM}$ were 4 -aminobenzoate, 2,3-dihydroxybenzoate, 2,5-dihydroxybenzoate, and 3-amino-4-hydroxybenzoate.

\section{DISCUSSION}

In this study, we purified 4-hydroxybenzoate 3-hydroxylase from $A$. calcoaceticus to homogeneity. To facilitate the purification, we overproduced this enzyme in $E$. coli. The conventional method for the overproduction of cloned genes, namely, the cloning of a gene of interest downstream of a strong promoter, did not realize our objective. We therefore devised a method to select variants which overexpressed the $p o b A$ gene. To perform this, we placed the folA gene of $P$. putida immediately downstream of the pobA gene, selected derivatives which overexpressed the folA gene, and hence exhibited higher resistance to trimethoprim. Such derivatives overexpressed the pobA gene. The trimethoprim resistance is not used as a marker in common cloning vectors, and the folA gene is small and easy to handle. The method used in this paper is therefore generally applicable to any other genes to increase their expression in $E$. coli or in other trimethoprim-sensitive bacteria.

The induced level of 4-hydroxybenzoate 3-hydroxylase in $A$. calcoaceticus corresponds to approximately $0.1 \%$ of the total protein. This amount is much less than the induced levels in $P$. fluorescens and $P$. aeruginosa. Apparently, 4-hydroxybenzoate 3-hydroxylase at a level of $0.1 \%$ of the total protein is sufficient to support the growth of $A$. calcoaceticus on 4-hydroxybenzoate.

Although the amino acid identity between 4-hydroxybenzoate 3-hydroxylase of $A$. calcoaceticus and the Pseudomonas enzymes is $63 \%$, most of the specific residues implicated for important functions, namely, FAD- and substrate-binding, are conserved between these enzymes (16). In agreement with the sequence data, we found that the properties of 4-hydroxybenzoate 3-hydroxylase from A. calcoaceticus are very similar to those of the Pseudo. monas enzymes.

It has been stated that 4-hydroxybenzoate 3-hydroxylase from $P$. desmolytica is inhibited by some organic acids, such as acetate, maleate, and propionate (30). In the Acinetobacter enzyme, however, acetate, malate, and succinate stimulated the enzymatic activity (Fig. 2 and our unpublished data). Apparently, spaces available for these solvent molecules differ between these two enzymes.

We found that the chloride ion is a non-competitive inhibitor of the 4-hydroxybenzoate 3-hydroxylase from $A$. calcoaceticus. The halide ions have been shown to be competitive inhibitors for NADPH of 4-hydroxybenzoate 3-hydroxylase from $P$. desmolytica $(30)$ and $P$. fluorescens (31). It is therefore possible that the NADPH-binding domain in the Acinetobacter enzyme is slightly different from those in the Pseudomonas enzymes. In spite of intensive studies on the $P$. fluorescens enzyme, the NADPH-binding site of this enzyme has not yet been identified, although it is assumed that NADPH binds to the re-side of the flavin, and that the nicotinamide moiety of NADPH may bind with its ring parallel to the flavin ring. It is therefore interesting to identify amino acid residues responsible for the sensitivity to the halide ions since one of these residues in $P$. fluorescens would overlap with the NADPH-binding domain, while in the Acinetobacter enzyme, the chloride ion-binding site and the NADPH-binding site may be separated. From the three-dimensional structure of the $P$. fluorescens enzyme, it is possible to identify several residues which can potentially interact with NADPH. Some of these residues are substituted in the Acinetobacter enzyme. Three replacements occur along the proposed cavity of NADPH binding $(6,32)$ : Val47Ile, Leu188Val, Leu261חle (numbered according to the $P$. fluorescens enzyme). In the latter two cases, the residue is either at the surface (Leu261), or faces away from the cavity (Leu188). One of them, the Val47Ile substitution, is a candidate for the residue responsible for the modification of the halide-ion-binding: the Val47Ile substitution together with neighbor Tyr385 may change the orientation of FAD, hence the electrostatic environment of the NADPHbinding site.

Our results with 3-chloro-4-hydroxybenzoate suggest that this compound is oxidized by 4-hydroxybenzoate 3 hydroxylase from $A$. calcoaceticus, but its oxidation was not efficient. There are two possible reasons to account for this. First, 3-chloro-4-hydroxybenzoate exhibits a low affinity to the enzyme as demonstrated by the limited FAD-absorbance change induced by this compound (our unpublished data). Certainly, the chloro-substitution causes a structural hindrance to binding. Leu199 and/or Tyr201 (numbering according to the $P$. fluorescens enzyme), which are located in the vicinity of the $\mathrm{C} 3$ atom of the substrate, may be responsible for it. Secondly, the electrodrawing nature of the chloro-substitution may in. hibit the electrophilic attack by $4 a$-hydroperoxide. More detailed study is required to elucidate the constraints of 4-hydroxybenzoate 3-hydroxylase for the oxidation of 3 chloro-4-hydroxybenzoate.

We thank M. Kok for supplying us the pBS618 plasmid, and E. Kim for help with computer analysis.

\section{REFERENCES}

1. Weijer, W.J., Hofsteenge, J., Vereijken, J.M., Jekel, P.A., and Beintema, J.J. (1982) Primary structure of $p$-hydroxybenzoate hydroxylase from Pseudomonas fluorescens. Biochim. Biophys. Acta 704, 385-388

2. Hofsteenge, J., Weijer, W.J., Jekel, P.A., and Beintema, J.J. (1983) $p$.Hydroxybenzoate hydroxylase from Pseudomonas fluorescens. 1. Completion of the elucidation of the primary 
structure. Eur. J. Biochem. 133, 91-108

3. Wijnans, R.A., Weijer, W.J., Muller, F., Jekel, P.A., van Berkel, W.J.H., and Beintema, J.J. (1986) Chemical modification of tyrosine residues in $p$-hydroxybenzaate hydroxylase from $P$ seudomonas fluorescens: Assignment in sequence and catalytic involvement. Biochemistry 25, 4211-4218

4. Entsch, B., Nan, Y., Weaich, K., and Scott, K.F. (1988) Sequence and organization of $p o b A$, the gene coding for $p$-hydroxybenzoate hydroxylase, an inducible enzyme from Pseudomonas aeruginosa. Gene 71, 279-291

5. van-Berkel, W.J.H., Westphal, A.H., Eschrich, K., Eppink, M., and de Kok, A. (1992) Substitution of Arg214 at the substratebinding site of $p$-hydroxybenzoate hydroxylase from Pseudomonas fluorescens. Eur. J. Biochem. 210, 411-419

6. Shuman, B. and Dix, T.A. (1993) Cloning, nucleotide sequence, and expression of a $p$-hydroxybenzoate hydroxylase. J. Biol. Chem. 268, 17057-17062

7. Wierenga, R.K., de Jong, R.J., Kalk, K.H., Hol, W.G.H., and Drenth, J. (1979) Crystal structure of $p$-hydroxybenzoate hydroxylase. J. Mol. Biol. 131, 55-73

8. Lar, M.S., Palfey, B.A., Schreuder, H.A., and Ludwig, M.L. (1994) Crystal structure of mutant Pseudomonas aeruginosa $p$-hydroxybenzaate hydroxylase: The Tyr201Phe, Tyr385Phe, and Asn300Asp variants. Biochemistry 39, 1555-1564

9. Schreuder, H.A., Prick, P.A., Wierenga, R.K., Vriend, G., Wilson, K.S., Hol, W.G.J., and Drenth, J. (1989) Crystal structure of $p$-hydroxybenzoate hydroxylase-substrate complex refined at $1.9 \mathrm{~A}$ resolution. Analysis of the enzyme-substrate and enzyme-product complexes. J. Mol. Biol. 208, 679-696

10. Schreuder, H.A., van der Laan, J.M., Swarte, M.B., Kalk, K.H., Hol, W.G.J., and Drenth, J. (1992) Crystal structure of the reduced form of $p$-hydroxybenzonte hydroxylase refined at $2.3 \AA$ resolution. Protein 14, 178-190

11. Schreuder, H.A., van der Laan, J.M., Hol, W.G.J., and Drenth, J. (1988) Crystal structure of $p$-hydroxybenzoate hydroxylase complexed with its reaction product 3,4-dihydroxybenzoate. $J$. Mol. Biol. 199, 637-648

12. Schreuder, H.A., Hol, W.G.J., and Drenth, J. (1990) Analysis of the active site of the flavoprotein $p$-hydroxybenzoate hydroxylase and some ideas with respect to its reaction mechanism. Biochemistry 29, 3101-3108

13. Entsch, B., Palfey, B.A., Ballou, D.P., and Massey, V. (1991) Catalytic function of tyrosine residues in para-hydroxybenzoate hydroxylase as determined by the study of site-directed mutants. J. Biol. Chem. 266, 17341-17349

14. Eschrich, K., van der Bolt, F.J., de Kok, A., and van Berkerl, W.J. (1993) Role of Tyr201 and Tyr385 in substrate activation by $p$-hydroxybenzoate hydroxylase from Pseudomonas fluores. cens. Eur. J. Biochem. 216, 137-146

15. Averhoff, B., Gregg-Jolly, L., Elsemore, D., and Ornston, L.N. (1992) Genetic analysis of supraoperonic clustering by use of natural transformation in Acinetobacter calcoacetucus. J. Bacteriol. 174, 200-204

16. DiMarco, A.A., Averhoff, B.A., Kim, E.E., and Ornston, L.N. (1993) Evolutionary divergence of $p o b A$, the structural gene encoding $p$-hydroxybenzoate hydroxylase in an Acinetobacter calcaaceticus strain well-suited for genetic analysis. Gene 125, 25-33

17. DiMarco, A.A., Averhoff, B., and Ornston, L.N. (1993) Identifi- cation of the transcriptional activator $p o b R$ and characterization of its role in the expression of pobA, the structural gene for p-hydroxybenzoate hydroxylase in Acinetobacter calcoaceticus. J. Bacteriol. 175, 4499-4506

18. Juni, E. and Janik, A. (1969) Transformation of Acinetobacter calco-aceticus (Bacterium anitratum). J. Bacteriol. 98, 281-288

19. Maniatis, T., Fritsch, E.F., and Sambrook, J. (1982) Molecular Cloning: A Laboratory Manual, Cold Spring Harbor Laboratories, Cold Spring Harbor, NY

20. Bauchop, T. and Eldsen, S.R. (1960) The growth of microorganisms in relation to their energy supply. J. Gen. Microbiol. 23, 457-469

21. Yanisch-Perron, C., Viera, J., and Messing, J. (1985) Improved M13 phage cloning vectors and host strains: Nucleotide sequences of the M13mp18 and pUC19 vectors. Gene 33, 103-119

22. Ausubel, F.M., Brent, R., Kingston, R.E., Moore, D.D., Seidman, J.G., Smith, J.A., and Struhl, K. (1990) Current Protocols in Molecular Biology, Green Publishing Associates \& Wiley-Interscience, New York

23. Ish-Horowicz, D. and Burke, J.F. (1981) Rapid and efficient cosmid cloning. Nucleic Acids Res. 9, 2989-2998

24. Bradford, M.M. (1976) A rapid and sensitive method for the quantification of microgram quantities of protein utilizing the principle of protein-dye binding. Anal. Biochem. 72, 248-254

25. Howell, L.G., Spector, T., and Massey, V. (1972) Purification and properties of $p$-hydroxybenzaate hydroxylase from Pseudomonas fluorescens. J. Biol. Chem. 247, 4340-4350

26. Muiller, F., Voordouw, G., van Berkel, W.J.H., Steennis, P.J., Visser, S., and van Rooijen, P.J. (1979) A study of $p$-hydroxybenzoate hydroxylase from Pseudomonas fluorescens. Improved purification, relative molecular mass, and amino acid composition. Eur. J. Biochem. 101, 235-244

27. Entsch, B. and Ballou, D.P. (1989) Purification, properties, and oxygen reactivity of $p$-hydroxybenzoate hydroxylase from Pseudomonas aerusinosa. Biochim. Biophys. Acta 999, 313-322

28. van Berkel, W.J.H. and Muller, F. (1989) The temperature and $\mathrm{pH}$ dependence of some properties of $p$-hydroxybenzoate hydroxylase from Pseudomonas fuorescens. Eur. J. Biochem. 179, 307314

29. van Berkel, W.J.H., and Muller, F. (1987) The elucidation of the microheterogeneity of highly purified $p$-hydroxybenzoate hydro. xylase from Pseudomonas fuorescens by various biochemical techniques. Eur. J. Biochem. 167, 35-46

30. Shoun, H., Arima, K., and Beppu, T. (1983) Inhibition of $p$ hydroxybenzoate hydroxylase by anions: Possible existence of two anion-binding sites in the site for reduced nicotineamide adenine dinucleotide phosphate. $J$. Biochem. 93, 169-176

31. Steennis, P.J., Cordes, M.M., Hilkens, J.G.H., and Muller, F. (1973) On the interaction of para-hydroxybenzoate hydroxylase from Pseudomonas fluorescens with halogen ions. FEBS Leth. 36, 177-180

32. van-Berkel, W.J.H., Muller, F., Jekel, P.A., Weijer, W.J., Schreuder, H.A., and Wierenga, R.K. (1988) Chemical modification of tyrosine-38 in $p$-hydroxybenzoate hydroxylase from Pseudomonas fuorescens by $5^{\prime}$-p -fluorosulfonylbenzoyladenosine: A probe for the elucidation of the NADPH binding site? Involvement in catalysis, assignment in sequence and fitting to the tertiary structure. Eur. J. Biochem. 176, 449-459 